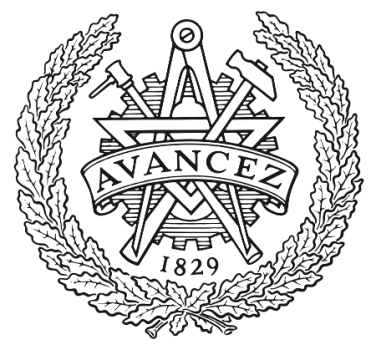

CHALMERS

UNIVERSITY OF TECHNOLOGY

\title{
Estimating weights for the active ageing index (AAI) from stated preferences: Proposal for a discrete choice experiment (DCE)
}

Downloaded from: https://research.chalmers.se, 2023-04-26 13:55 UTC

Citation for the original published paper (version of record):

Boehler, C., Helter, T., Rohman, I. et al (2018). Estimating weights for the active ageing index (AAI) from stated preferences: Proposal for a discrete choice experiment (DCE). Building Evidence for Active Ageing Policies: Active Ageing Index and its Potential: 239-258. http://dx.doi.org/10.1007/978-981-10-6017-5_12

N.B. When citing this work, cite the original published paper. 


\title{
12
}

\section{Estimating Weights for the Active Ageing Index (AAI) from Stated Preferences: Proposal for a Discrete Choice Experiment (DCE)}

\author{
Christian Ernst Heinrich Boehler, \\ Timea Mariann Helter, Ibrahim-Kholilul Rohman, \\ and Fabienne Abadie
}

\subsection{Introduction}

Demographic change is a major societal challenge for EU Member States, which may increase demand for health and care services and socioeconomic inequalities (WHO 2002; EC 2012). In this context, Active and

The views expressed in this chapter are those of the authors and may not in any circumstances be regarded as stating an official position of the European Commission. The authors would like to thank Csaba Kucsera, Rene van Bavel and Ioannis Maghiros for their contributions and take full responsibility for all remaining errors and shortcomings of this chapter.

C.E.H. Boehler $(\bowtie)$

European Centre for Social Welfare Policy and Research, Vienna, Austria

T.M. Helter

Main Association of Austrian Social Security Institutions, Vienna, Austria

I.-K. Rohman

Chalmers University of Technology, Göteborg, Sweden

F. Abadie

DG JRC-IPTS, European Commission, Sevilla, Spain 
Healthy Ageing (AHA) has been identified as a EU policy priority, and an opportunity to strengthen the sustainability of health and care systems and improve the health of older people, allowing them to participate in employment and society (EC 2006). Many initiatives on Active and Healthy Ageing are underway across Europe, most prominently the European Innovation Partnership on Active and Healthy Ageing (EIP on AHA) (EC 2011), and several concepts are being developed to assess active ageing policies and interventions. For instance, the monitoring framework for the EIP on AHA seeks to extrapolate outcomes from individual interventions in terms of health-related quality of life and health and care expenditure in a bottom-up approach (Boehler and Abadie 2015; Boehler et al. 2015). Another concept, which incorporates information from macrolevel indicators drawn from comparative international datasets, is the Active Ageing Index (AAI) (Zaidi et al. 2013; Zaidi and Stanton 2015).

The AAI is a composite indicator reflecting the multidimensional character of active ageing (Zaidi et al. 2013). It combines information on 22 indicators drawn from the EU-SILC (Survey of Income and Living Conditions), the EU-LFS (Labour Force Survey) and the European Quality of Life Survey (EQLS). These are grouped in four domains related to healthy and independent living and more active participation in employment and society (Zaidi et al. 2013). The AAI indicators and domains are linearly aggregated using constant weights elicited from a group of experts. The AAI-Expert Group (2014, p. 4) recently 'expressed their concerns about the arbitrary weighting of indicators and domains'.

This chapter discusses the opportunity to further AAI methods regarding the weighting issue and suggests an approach for basing complementary weight sets on stated preferences. We propose using Discrete Choice Experiments (DCEs) and outline how this could be implemented across different population subgroups and geographic contexts. DCEs 'force respondents to make trade-offs among different choice sets, unlike other methods such as ranking or rating' (Wong et al. 2014, p. 2), which may provide more credible information on the relative importance of each indicator in the Index. The chapter addresses the relevance and feasibility of DCEs to define alternative weights for the AAI, but does not report actual DCE results.

The next section reviews the existing weighting system and introduces DCEs as a promising method to estimate complementary, preference- 
based AAI weights. Section 12.3 outlines the design of a potential DCE to estimate such preference-based weights. In the discussion, we consider the benefits of increasing the flexibility of the AAI as a tool for policy evaluation, by providing complementary weight sets suitable for subgroup, scenario and sensitivity analyses of AAI results. We further discuss the validity of stated preferences, especially when respondents are not active ageing policy experts (e.g. general population). In this context, we stress the importance of an underlying theoretical construct for empirically estimating weights and discuss factors influencing the resources required for conducting the proposed DCE.

\subsection{Estimating Preference-based Weights for the AAI}

Composite indicator weights constitute value judgements and many statistical or participatory methods allow their estimation (OECD/JRC 2005). They should be derived based on an underlying theoretical framework, and both 'correlation and compensability issues among indicators need to be considered and either be corrected for or treated as features of the phenomenon that need to be retained in the analysis' (OECD/JRC 2005, p. 15). The current AAI weight set is particularly useful as expert opinion is essential to ensure adequate consideration of existing policy priorities, theoretical factors or budget constraints (OECD/JRC 2005). Further, transparency and comparability are key features of composite indicators (OECD/JRC 2005), which make constant weights particularly appealing for comparative country analysis, a key objective of the AAI (Zaidi et al. 2013; Zaidi and Stanton 2015). However, expert-based weights may induce bias and not reflect actual preferences of the target population, whilst constant weights may sometimes provide adverse incentives for policymakers (OECD/JRC 2005; Sharpe and Andrews 2012). Such concerns were recently raised about the AAI (AAI-Expert Group 2014).

For instance, the current AAI weighting system does not consider opportunity costs and marginal substitution rates between indicators. However, according to consumer theory, the marginal utility from increasing the score of an indicator should be higher if its current score is 
low (Fig. 12.1) (OECD/JRC 2005). Hence, if a particular AAI indicator has a low value, compensation through other indicators should be more difficult (OECD/JRC 2005). Moreover, if the optimal score of an indicator is below $100 \%$, an increase beyond the optimum should be counterbalanced through negative weights (Fig. 12.1). Constant AAI weights may therefore lead policymakers to maximise scores for indicators and domains which are comparatively easier to increase. Further, AAI results based on constant weights ignore distributional aspects and may underestimate the burden associated with low scores for a particular indicator in disadvantaged populations, whilst overestimating it in others. Preference-based weights could therefore help provide greater incentives to address problems in underserved populations (Fig. 12.1). Finally, expert-based constant weights have no theoretical foundation, and may not reflect what people actually want in different social, cultural or geographic contexts. The importance of citizens' voice in public policy and planning being increasingly recognised (Cogan et al. 1986), citizens' participation should be intrinsic to active ageing policies, and the AAI could

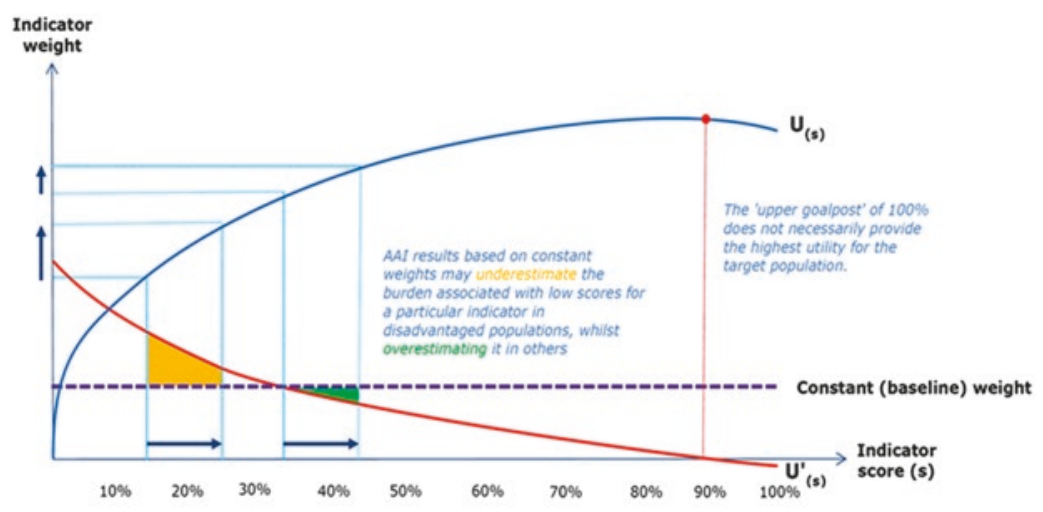

The population utility for an indicator or domain of the AAI is represented by U(s). The utility gain from increasing the indicator score by the same amount would be higher at lower absolute indicator scores, as indicated by the blue arrows. Likewise, compensation through other indicators would be more difficult if the absolute indicator score is low so that the positive impact on the overall index is higher when improving on policy areas which are particularly underserved. The weight for the indicator would be estimated from the derivative of the utility function U(s), the marginal utility function $U^{\prime}(s)$. The score of an indicator that provides the highest utility does not necessarily match the upper goalpost of $100 \%$, so that increasing the indicator score beyond the maximum should even be weighted negatively.

Source: own drawing

Fig. 12.1 Preference-based weights reflecting diminishing marginal utility of increasing indicator scores 
gain from reflecting public preferences. Decision makers should then ensure that public participation leads to better planning and prioritisation, safeguarding citizen' interest.

The key issue is how to empirically estimate preference-based AAI weights. DCEs seem promising as a method to improve the evaluation of active and healthy ageing policies and interventions. The concept is based upon Random Utility Theory and the assumptions that (Lancaster 1966, p. 134):

- 'The good, per se, does not give utility to the consumer; it possesses characteristics, and these characteristics give rise to utility': The AAI components (characteristics) contribute to the utility realised by members of the target population of active ageing policies and interventions (the good).

- 'In general, a good will possess more than one characteristic, and many characteristics will be shared by more than one good': The AAI comprises several component-indicators, and different active ageing policies and interventions may affect different subsets of components.

- 'Goods in combination may possess characteristics different from those pertaining to the goods separately': The utility of the target population derived from policies impacting several AAI components may differ from the sum of the utilities influenced by policies and interventions targeting each component separately.

In DCEs, respondents are given hypothetical scenarios representing competing alternatives (here active ageing policies or interventions) whose attributes (potential determinants of active and healthy ageing) vary (Lancsar and Louviere 2008). Their purpose is to estimate a utility function of the type (Amaya-Amaya et al. 2008):

$$
U_{i n}=A S C_{i}+\beta_{1} X_{i 1}+\beta_{2} X_{i 2}+\ldots+\beta_{k} X_{i k}+\varepsilon_{i n}
$$

where ' $A S C_{i}^{\prime}$ is the 'alternative specific constant', ' $k$ ' $(=1,2, \ldots K)$ represents the number of attributes with coefficients ' $\beta_{k}$ ' to be estimated across alternatives ' $i$ ' and respondents ' $n$ ', and ' $\varepsilon$ ' represents unmeasured random variation in respondents' preferences for different alternatives 
(Amaya-Amaya et al. 2008). The information obtained could help estimate AAI weights, especially (Ryan and Farrar 2000):

- The direction of the effect of a change in attribute levels, for example, whether respondents prefer an increase in the use of ICT over a reduction

- The relative importance of one attribute over another, for example, whether improving access to health services is valued higher than greater political participation

- The trade-off or marginal substitution rate between attributes, that is, to what extent people would accept decreasing one attribute (e.g. employment) to increase another one (e.g. financial (in)security) at different attribute levels

DCEs can potentially reveal how attributes influence respondents' choice or decision (Scott 2002), and what utilities they attach to different levels of achievement for each attribute (Lancsar and Louviere 2008; Mangham et al. 2009). DCEs are therefore promising for estimating AAI weights as the value of active ageing to an individual can be defined by a set of attributes reflecting the multidimensional character of active ageing and the composite character of the Index.

\subsection{Designing a DCE to Estimate Preference- based AAl Weights}

Several authors described the steps for developing DCEs (Fig. 12.2), and unanimously highlighted that decisions taken in each stage may have downstream implications for subsequent stages of the experiment (e.g. Amaya-Amaya et al. 2008; Viney et al. 2002; Bridges et al. 2011; Johnson et al. 2013). In this section, we discuss the key elements for a DCE to estimate preference-based AAI weights. 


\section{Problem definition: characterising the choice decision}

\section{Identifying relevant attributes and attribute levels}

\section{Experimental design and construction of choice-sets}

\section{Experimental context and questionnaire development}

\section{Model estimation}

\section{Policy analysis}

Fig. 12.2 Key stages for developing a Discrete Choice Experiment (adapted from Amaya-Amaya et al. 2008)

\subsubsection{Problem Definition: Characterising the Choice Decision}

Developing a DCE starts with considering explicitly how individuals make decisions about the problem in question and which dimensions driving the choice process to include as attributes (Amaya-Amaya et al. 2008; Bridges et al. 2011). The 22 indicators composing the AAI predetermine our list of potential attributes for a DCE as we assume that they provide a meaningful, measurable and comprehensive list of active ageing determinants.

Another issue regarding the choice decision is to 'identify the possible choosers' and potential sources of variability across individuals, such as gender or socioeconomic characteristics, which could become explanatories for behavioural differences (Amaya-Amaya et al. 2008). Regarding potential choosers, several sources of opinions could help ascertain which outcomes of active ageing policies and interventions matter to people 
(e.g. Dolan 1999; Shumway et al. 2003; Ubel et al. 2003; Watson et al. 2012). For instance, priorities could be elicited from:

- The general public whose tax contributions provide funding for such policies and interventions.

- The ageing population being recipients of active ageing policies, their preferences should be considered when prioritising different outcomes.

- Policy planners and policymakers are responsible for policy setting and thus may influence future decision-making processes.

- As with the current weighing methodology, experts on active ageing policies and interventions could also be consulted on how to prioritise outcomes in various policy decisions.

\subsubsection{Identifying Attributes and Attribute Levels}

Various methods have been used or suggested for identifying attributes for DCEs. Helter and Boehler (2016) distinguish four general stages of attribute development: raw data collection, data reduction, removing inappropriate attributes and wording.

Though the list of potential attributes derives from the 22 indicators composing the index, further refinement may be required. Whilst all attributes influencing an individual's decision should be included (Coast et al. 2012), DCEs should generally have a maximum of six or seven attributes to reduce the cognitive burden on respondents (e.g. Ryan and Gerard 2003). Further, attributes should be salient, plausible and capable of being traded (Ryan 1999); they should not be too close to the latent construct investigated or dominant for a decision; and they should not be intrinsic to a person's personality and experimentally 'manipulable' by the intervention (Coast et al. 2012).

To reduce the number of attributes, some AAI indicators like employment rates for different age cohorts could be merged, and differential weights assigned according to the relative importance different respondents (e.g. from different age cohorts) place on employment. Further, 'relative mean income', 'poverty risk' and 'severe material deprivation' 
could merge into 'financial security' as their correlation is probably high and their capability of being traded against each other doubtful. Attributes could also be divided into separate blocks and different choice sets presented to different respondents (Viney et al. 2002; Street et al. 2008), as discussed below.

Equally important for the proposed DCE are the attribute levels (Lancsar and Louviere 2008). Levels may be categorical (e.g. degree of physical safety) or continuous (e.g. relative median income), and attributes can have different numbers of levels (WHO 2012; Huber and Zwerina 1996). Indeed, attribute levels are particularly important as the current AAI implies a linear and flat relationship between indicator scores and active ageing outcomes, as Fig. 12.1 shows (Zaidi et al. 2013; Zaidi and Stanton 2015). However, whilst a greater number of levels increases the ability to detect non-linear marginal utility relationships, so does complexity as possible attribute-level combinations increase exponentially, which impacts the experimental design of the DCE (Huber and Zwerina 1996).

\subsubsection{Experimental Design and Construction of Choice Sets}

This is about combining attributes and levels into different alternatives (e.g. potential outcomes of competing policy interventions) and choice sets (of at least two competing alternatives) to be presented to respondents (Ryan and Farrar 2000). Figure 12.3 shows an exemplary choice question for indicators of the second AAI domain.

Johnson et al. (2013, p. 5) state that 'the experimental-design step consists of defining a systematic plan that determines the content of the choice questions to generate the variation in the attribute levels required to elicit a choice response'. The aim is to select, among all possible attribute-level combinations (or 'full factorial design'), a subset providing the best balance between obtaining reliable parameter estimates and limitations to the number of potential alternatives (Mangham et al. 2009). A full factorial design would provide respondents with too many choice sets and pose an unmanageable cognitive burden (Street et al. 2008; Louviere 
Below are the outcomes of two competing policy interventions to improve participation in society. Which alternative would you prefer depending on the current score of each indicator?

\begin{tabular}{|c|c|c|}
\hline Attributes (indicators) & Policy intervention A & Policy intervention B \\
\hline Voluntary activities & $10 \%$ up & unchanged \\
\hline Care to children, grandchildren & $5 \%$ up & unchanged \\
\hline Care to older adults & unchanged & $10 \%$ down \\
\hline \multicolumn{2}{|c|}{ Political participation } & unchanged \\
\hline $\begin{array}{l}\text { Note that this example has been constructed for demonstrative purposes only. Different level definitions and } \\
\text { customisation to different populations or geographic contexts (e.g. by linking attribute levels to current indicator } \\
\text { scores within each geographic setting), is possible for different attributes. }\end{array}$
\end{tabular}

Fig. 12.3 Potential choice question for participation in society

et al. 2000). Amaya-Amaya et al. (2008, p. 19) suggest that 'the number of combinations chosen should be equal or greater than the number of parameters the analyst is likely to estimate from the data collected'. Further, the number and types of parameters to be estimated depend on the model specification, the number of attributes and levels, and the functional form of the attributes (Johnson et al. 2013).

The AAI structure with indicators grouped in four domains of active and healthy ageing suits an experimental design which assigns respondents randomly to different blocks of choice questions, as depicted in Fig. 12.4 (Viney et al. 2002; Street et al. 2008): choice sets in each block would comprise attributes from each AAI domain and across domains, respectively. The weights ' $w(s, x)_{i, j}$ ' for each indicator $(i)$ in block $(j)$ depend on the marginal rate of substitution at different indicator scores $(s)$ and a vector of covariates $(x)$ denoting relevant population characteristics (e.g. age or gender). A blocked design may reduce the complexity of the choice task and the cognitive burden on respondents whilst providing a full preference-based weight set for the Index. 


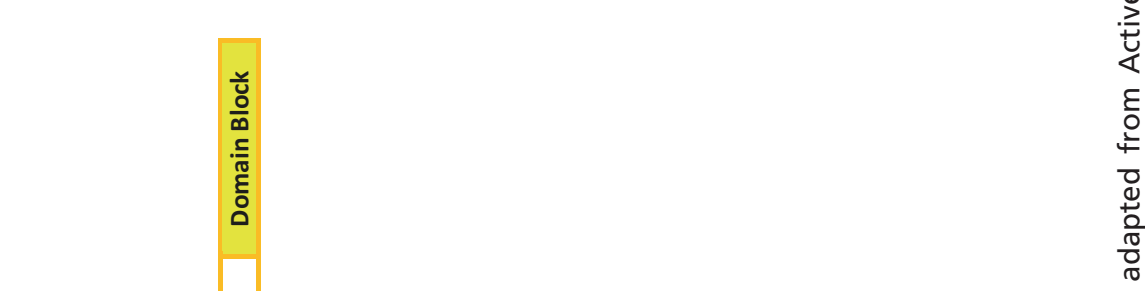

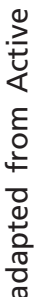

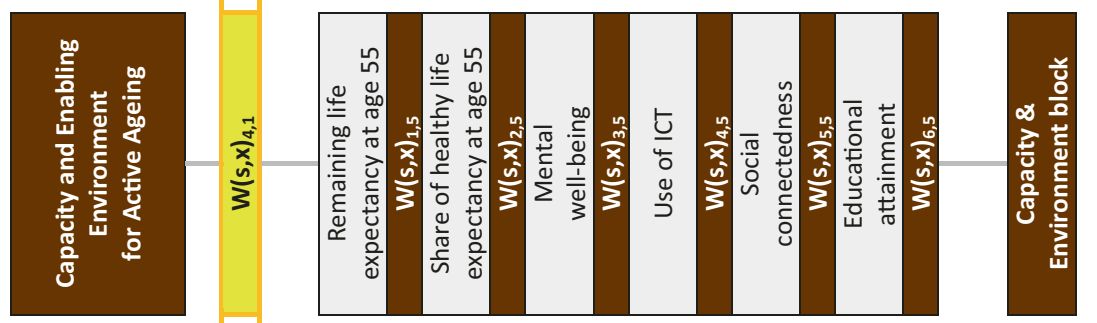

일 ํํㅇ

을 운 $\frac{0}{\stackrel{0}{0}} \stackrel{+}{x}$

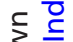
○े نं $\cdot \frac{\varsigma}{0}$

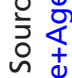

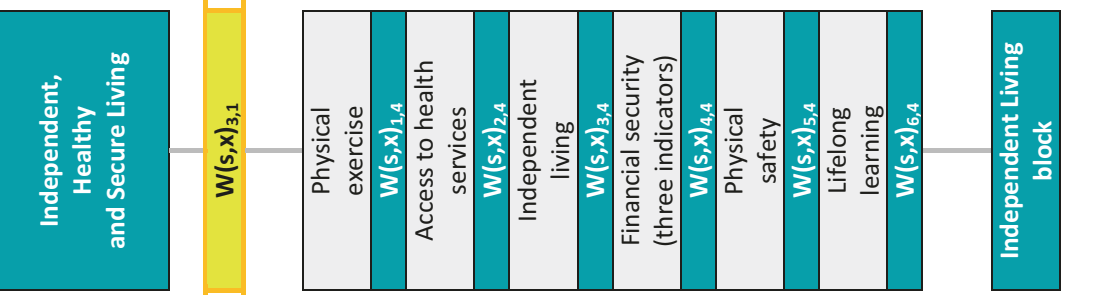

i் ธิ $3 \frac{1}{3}$ ষ 웡 뜽 ڤ ㅇํㅇ 㟧 这
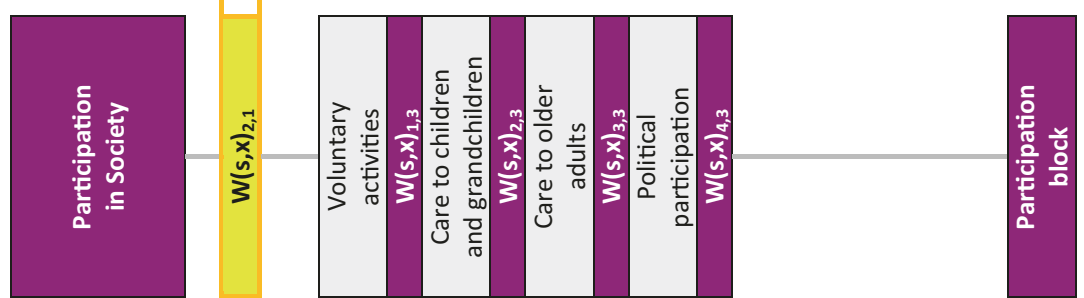
造 प⿺辶 흐 음 ๑ 음 0 हู త્త 䒕 至 $+5$ ธ 온
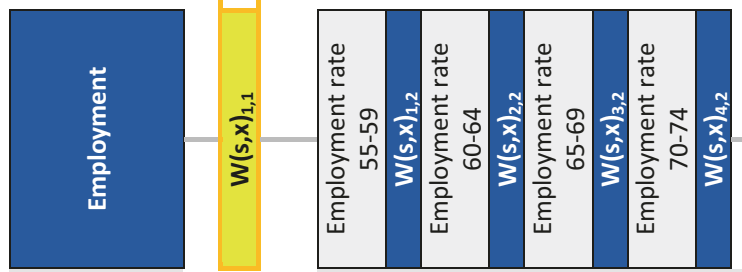

suḷemoc

sıołeว!pu|

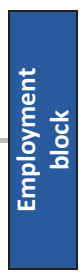
过 岂 口元 웜 $\frac{0}{0}$ 늠 응 $\checkmark \subseteq$ 음 도 훈 宁 


\subsubsection{Questionnaire Development and Model Estimation}

The labelling of alternatives, the administration mode and the quantitative modelling methods to estimate indicator weights from the choice responses are some additional issues for consideration (e.g. Amaya-Amaya et al. 2008; Bridges et al. 2011; WHO 2012).

Labelled alternatives (e.g. 'improving occupational safety' vs. 'improving quality of part-time work') can reduce the cognitive burden on respondents as the choice presented is clearer. However, the emphasis may shift away from attributes and levels towards the policy interventions themselves, reducing the focus on potential trade-offs between attributes (Louviere et al. 2000; De Bekker Grob et al. 2010; WHO 2012). Generic alternatives as in Fig. 12.3 (i.e. 'policy intervention $A$ ' vs. 'policy intervention $B$ ) allow respondents to focus exclusively on attributes and levels, which matters for estimating marginal substitution rates (Louviere et al. 2000).

Also important for the proposed DCE is the mode of administration (Bridges et al. 2011). Digital competencies and the use of information and communication technologies decrease with age (Eurostat 2015), potentially affecting the validity of the DCE if the mode of administration induces selection bias. It is also important to pre-test the planned DCE to ensure that the words and expressions used are understood unequivocally by everyone, and to obtain information about potential correlations between attributes which would make trade-offs impossible (Coast et al. 2012).

Finally, when conducting the proposed DCE, it will be crucial to determine an appropriate model to estimate parameters for measuring the random utility between outcome-alternatives from the data obtained (WHO 2012). The cross-sectional panel design of the choice data and within-subject correlation (Bridges et al. 2011; Train 2009) require particular attention. Further, preferences may vary systematically between population subgroups, which could be addressed through covariates (e.g. gender and socioeconomic characteristics) and interactions with attributes (Bridges et al. 2011). Models widely used in the context of DCEs are multinomial logit models (MNL) (McFadden 1974) which can account for both the panel structure of the data and potential preference 
variation (Bridges et al. 2011; Train 2009). A whole body of literature exists around model estimation for DCEs and available options to relax the assumptions of the MNL (Train 2009).

\subsection{Discussion and Conclusion}

The aim of the AAI is to produce high-quality, independent evidence to evaluate and compare outcomes from a diverse range of policies targeting active and healthy ageing. We believe that the AAI can achieve this but hope to contribute to its further development by proposing DCEs for estimating complementary weight sets. Indeed, we do not advocate replacing the existing expert-based and constant weights as expert opinion is essential for policy evaluation, and constant weights ensure transparency and comparability, particularly for cross-country analysis. Our intention is rather to provide additional options for conducting policyrelevant analyses through the AAI, thereby improving the evidence base upon which to evaluate active ageing policies. A DCE could provide alternative weights from stated preferences which also recognise potential trade-offs between the indicators and domains of the Index. This could deepen our understanding of the potential impact of alternative active ageing policies in various contexts and further enhance the acceptance of the Index through citizens' participation.

Participatory methods for eliciting composite indicator weights help incorporating the views of various stakeholders, such as the general population, the target cohort of active ageing policies, policymakers, or active and healthy ageing experts. The methodological literature for composite indicator development suggests a variety of participatory methods for weight development, including among others budget allocation process, analytic hierarchy process and conjoint analysis (CA) (OECD/JRC 2005). DCEs are often called a variant of CA as both methods confront individuals with choices between alternative goods and services that vary along several attributes and levels (Louviere et al. 2010). However, DCEs are, unlike traditional CA, thoroughly rooted in Random Utility Theory (Lancaster 1966), which assumes that utility is a latent construct in a person's mind that cannot be observed by the researcher (Louviere et al. 2010). 
A potential objection to our approach relates to whether survey-based estimates can provide relevant and meaningful information for estimating AAI weights, especially when elicited from lay people rather than experts of active ageing policies. Survey-based preference estimates may raise scepticism when results 'seem inconsistent with economic intuition' and may be interpreted as evidence of (a) the hypothetical nature of the question, (b) strategic behaviour, or (c) preferences which are either ill-defined or inconsistent with economic theory' (Carson and Groves 2007, p. 182). In other words, respondents do not always answer a question truthfully, and neither do they always understand the question posed correctly (Carson and Groves 2007). This reinforces the importance of an underlying theoretical construct. Random Utility Theory assumes that utilities consist of a systematic (explainable) component and a random (unexplainable) component which comprises all unidentified factors that impact individual choices (Louviere et al. 2010). It further assumes that individuals are 'imperfect measurement devices', hence, the random component may reflect 'variability and differences in choices associated with individuals and not choice options per se' (Louviere et al. 2010, p. 62.) We can therefore predict the probability that an individual chooses one alternative over another, but never the exact alternative an individual will choose (Louviere et al. 2010). We can investigate different types of information or strategic incentives used in DCEs and their impact on respective responses so as to assess changes in consumer behaviour in response to changes in the choice context (Louviere et al. 2010). We can also externally validate trade-offs made in DCEs through comparison with trade-offs observed elsewhere (such as real market behaviour) (Louviere et al. 2010; Carson and Groves 2007). Hence, DCEs may not only allow assessing the variability in choices through covariates representing differences in individual choosers (which would matter for subgroup analysis of AAI weights), but also potential causes of bias in choice responses (Louviere et al. 2010).

Finally, it is also important to consider key elements of the study design likely to drive the cost of implementing the proposed DCE, such as the size of the sample required for estimating preference-based AAI weights that allow for both marginal substitution rates between indicators and disaggregation of subgroups and geographic contexts. It is difficult to estimate ad hoc the sample size required as it depends on several issues 
discussed here: such as the question format, the complexity of the choice tasks, the desired degree of precision, heterogeneity in the target population and the need for subgroup analysis (Bridges et al. 2011; Louviere et al. 2000). Methods are available for sample size estimation (Louviere et al. 2000) and the overall population size actually plays a relatively small role in these calculations (Amaya-Amaya et al. 2008). The mean sample size for health-related DCEs published between 2005 and 2008 was 259 (Marshall et al. 2010), and Johnson et al. (2013) state that 'sample sizes in the range of 1000 to 2000 will produce small confidence intervals' (p. 6). Further, to demonstrate the value of preference-based AAI weights in the context of cross-country analysis, the experiment would have to be conducted in different geographic domains, with obvious implications for the overall number of respondents required and additional resources needed for customising questionnaires to different contexts (e.g. translations, data collection in different countries). Finally, the mode of administration is likely to increase the resources required, as a self-administered, computer-based format without face-to-face contact may be inadequate for some groups of respondents. This may also require more extensive pre-testing of the questionnaire, which in turn affects costs.

In conclusion, we believe that our proposed DCE can enhance the AAI as an effective tool for policymaking. Preference-based weights account for potential trade-offs and marginal substitution rates between indicators, and our proposed method allows including the views of different groups of stakeholders in evaluating policy outcomes. We think that our approach can complement the current AAI methodology, enhance its flexibility and improve our understanding of what people actually want in different social, cultural or geographic contexts, thus helping to define more targeted active and healthy ageing policies.

\section{References}

AAI-Expert Group. (2014). Report of the third meeting of the AAI Expert Group. Brussels, Belgium. Retrieved from http://wwwl.unece.org/stat/platform/ download/attachments/76287849/Report\%20of\%20the\%20Third\%20 meeting_Final.pdf?version=1\&modificationDate=1395409157483\&api=v2 
Amaya-Amaya, M., Gerard, K., \& Ryan, M. (2008). Discrete choice experiments in a nutshell. In M. Ryan, K. Gerard, \& M. Amaya-Amaya (Eds.), Using discrete choice experiments to value health and healthcare. Dordrecht: Springer.

Boehler, C., \& Abadie, F. (2015). Monitoring and Assessment Framework for the European Innovation Partnership on Active and Healthy Ageing (MAFEIP). Conceptual description of the monitoring framework. European Commission, Joint Research Centre, Seville, Spain. ISBN:978-92-79-50574-4. Retrieved from http://publications.jrc.ec.europa.eu/repository/handle/JRC96205

Boehler, C., de Graaf, G., Steuten, L., Yang, Y., \& Abadie, F. (2015, September). Development of a web-based tool for the assessment of health and economic outcomes of the European Innovation Partnership on Active and Healthy Ageing (EIP on AHA). BMCMedical Informatics and Decision Making, 15(Suppl. 3), S4. Retrieved from http://www.biomedcentral.com/1472-6947/15/S3/S4 Bridges, J. F., Hauber, A. B., Marshall, D., Lloyd, A., Prosser, L. A., Regier, D. A., Johnson, F. R., \& Mauskopf, J. (2011). Conjoint analysis applications in health-a checklist: Report of the ISPOR good research practices for conjoint analysis task force. Value in Health, 14(4), 403-413. Retrieved from http://www.ispor.org/taskforces/documents/ISPOR-CA-in-Health-TFReport-Checklist.pdf

Carson, R. T., \& Groves, T. (2007). Incentive and informational properties of preference questions. Environmental and Resource Economics, 37, 181-200.

Coast, J., Al-Janabi, H., Sutton, E. J., Horrocks, S. A., Vosper, A. J., Swancutt, D. R., \& Flynn, T. N. (2012). Using qualitative methods for attribute development for discrete choice experiments: Issues and recommendations. Health Economics, 21(6), 730-741.

Cogan, A., Sharpe, S., \& Hertzberg, J. (1986). “Citizen Participation.” The practice of state and regional planning. Chicago.

De Bekker-Grob, E. W., Hol, L., Donkers, B., van Dam, L., Habbema, J. D., van Leerdam, M. E., Kuipers, E. J., Essink-Bot, M. L., \& Steyerberg, E. W. (2010). Labeled versus unlabeled discrete choice experiments in health economics: An application to colorectal cancer screening. Value in Health, 13(2), 315-323.

Dolan, P. (1999). Whose preferences count? Medical Decision Making, 19(4), 482-486.

European Commission. (2006). The demographic future of Europe-From challenge to opportunity. COM/2006/0571. Retrieved from http://eur-lex.europa. eu/legal-content/EN/ALL/ELX_SESSIONID=X5cbJ7hYDFQjnJHrLT7L MD1nPSNcrVk1ZmvhnnXgkVLvX0Ln11Qw!-82020822?uri=CELEX:52 $006 \mathrm{DC} 0571$ 
European Commission. (2011). Strategic implementation plan for the European innovation partnership on active and healthy ageing. Steering Group Working Document. Retrieved from http://ec.europa.eu/research/innovation-union/ pdf/active-healthy-ageing/steering-group/implementation_plan.pdf\#view=fi t\&pagemode=none

European Commission. (2012). The 2012 Ageing Report, Economic and budgetary projections for the 27 EU Member States (2010-2060). European Economy 2/2012. Retrieved from http://ec.europa.eu/economy_finance/publications/ european_economy/2012/pdf/ee-2012-2_en.pdf

Eurostat. (2015). Information society statistics. Retrieved January 21, 2015, from http://ec.europa.eu/eurostat/web/information-society/data/database

Helter, T. M., \& Boehler, C. (2016). Developing attributes for discrete choice experiments in health-A systematic literature review and case study of alcohol misuse interventions. Journal for Substance Use, 21(6), 662-668.

Huber, J., \& Zwerina, K. (1996). The importance of utility balance in efficient choice designs. Journal of Marketing Research, 33, 307-317.

Johnson, F. R., Lancsar, E., Marshall, D., Kilambi, V., Mühlbacher, A., Regier, D. A., Bresnahan, B. W., Kanninen, B., \& Bridges, J. F. (2013). Constructing experimental designs for discrete-choice experiments: Report of the ISPOR conjoint analysis experimental design good research practices task force. Value in Health, 16, 3-13. Retrieved from http://www.ispor.org/ ValueInHealth/ShowValueInHealth.aspx?issue=3551E3F3-83A8-48959415-5272AF29A9DF.

Lancaster, K. J. (1966). A new approach to consumer theory. Journal of Political Economy, 74(2), 132-157. Retrieved from http://www.dklevine.com/archive/ refs41385.pdf.

Lancsar, E., \& Louviere, J. (2008). Conducting discrete choice experiments to inform healthcare decision making: A user's guide. PharmacoEconomics, 26(8), 661-677.

Louviere, J., Hensher, D. A., \& Swait, J. D. (2000). Stated choice methods: Analysis and applications. Cambridge: Cambridge University Press.

Louviere, J. J., Flynn, T. N., \& Carson, R. T. (2010). Discrete choice experiments are not conjoint analysis. Journal of Choice Modelling, 3(3), 57-72.

Mangham, L. J., Hanson, K., \& McPake, B. (2009). How to do (or not to do)....Designing a discrete choice experiment for application in a lowincome country. Health Policy and Planning, 24, 151-158.

Marshall, D., Bridges, J. F. P., Hauber, B., Cameron, R., Donnalley, L., Fyie, K., \& Johnson, F. R. (2010). Conjoint analysis applications in health-How are 
studies being designed and reported? The Patient: Patient-Centered Outcomes Research, 3(4), 249-256.

McFadden, D. (1974). Conditional logit analysis of qualitative choice behavior. In P. Zarembka (Ed.), Frontiers of econometrics. New York: Academic Press.

OECD/JRC. (2005). Handbook of constructing composite indicators: Methodology and user guide. OECD Statistics Working Paper. Retrieved from http://www. oecd.org/std/42495745.pdf

Ryan, M. (1999). Using conjoint analysis to take account of patient preferences and go beyond health outcomes: An application to in vitro fertilisation. Social Science and Medicine, 48(4), 535-546.

Ryan, M., \& Farrar, S. (2000). Using conjoint analysis to elicit preferences for healthcare. BMJ, 320, 1530-1533.

Ryan, M., \& Gerard, K. (2003). Using discrete choice experiments to value health care programmes: Current practice and future research reflections. Applied Health Economics and Health Policy, 2(1), 55-64.

Scott, A. (2002). Identifying and analysing dominant preferences in discrete choice experiments: An application in healthcare. Journal of Economic Psychology, 23(3), 383-398.

Sharpe, A., \& Andrews, B. (2012). An assessment of weighting methodologies for composite indicators: The case of the index of economic well-being. CSLS Research Report 2012-10. Retrieved from http://www.csls.ca/reports/ csls2012-10.pdf

Shumway, M., Saunders, T., Shern, D., Pines, E., Downs, A., Burbine, T., \& Beller, J. (2003). Preferences for schizophrenia treatment outcomes among public policy makers, consumers, families, and providers. Psychiatric Services, 54(8), 1124-1128.

Street, D., Burgess, L., Viney, R., \& Louviere, J. (2008). Designing discrete choice experiments for healthcare. In M. Ryan, K. Gerard, \& M. AmayaAmaya (Eds.), Using discrete choice experiments to value health and healthcare. Dordrecht: Springer.

Train, K. (2009). Discrete choice methods with simulation (2nd ed.). Cambridge: Cambridge University Press.

Ubel, P. A., Loewenstein, G., \& Jepson, C. (2003). Whose quality of life? A commentary exploring discrepancies between health state evaluations of patients and the general public. Quality of Life Research, 12(6), 599-607.

Viney, R., Lancsar, E., \& Louviere, J. (2002). Discrete choice experiments to measure consumer preferences for health and healthcare. Expert Review of Pharmacoeconomics Outcomes Research, 2(4), 319-326. 
Watson, V., Carnon, A., Ryan, M., \& Cox, D. (2012). Involving the public in priority setting: A case study using discrete choice experiments. Journal of Public Health, 34(2), 253-260. Retrieved from http://jpubhealth.oxfordjournals.org/content/34/2/253.full.pdf+html.

WHO. (2002). Active ageing: A policy framework. WHO/NMH/NPH/02.8. Retreievd from http://whqlibdoc.who.int/hq/2002/WHO_NMH_NPH_ 02.8.pdf?ua $=1$

WHO. (2012). How to conduct a discrete choice experiment for health workforce recruitment and retention in remote and rural areas: A user guide with case studies. Retrieved from http://www.who.int/hrh/resources/dceguide/en/

Wong, S. F., Norman, R., Dunning, T. L., Ashley, D. M., \& Lorgelly, P. K. (2014). A protocol for a discrete choice experiment: Understanding preferences of patients with cancer towards their cancer care across metropolitan and rural regions in Australia. BMJ Open, 4, e006661. Retrieved from http:// bmjopen.bmj.com/content/4/10/e006661.full.pdf+html

Zaidi, A., Gasior, K., Hofmarcher, M. M., Lelkes, O., Marin, B., Rodrigues, R., Schmidt, A., Vanhuysse, P., \& Zolyomi, E. (2013). Active Ageing Index 2012. Concept, methodology, and final results. Research Memorandum/Methodology Report. European Centre Vienna, March 2013. Retrieved from www.euro. centre.org/data/aai/1253897823_70974.pdf

Zaidi, A., \& Stanton, D. (2015). Active ageing index 2014: Analytical report. Report produced at the Centre for Research on ageing, University of Southampton, under contract with UNECE (Geneva), co-funded by European Commission, Brussels. Retrieved from http://www.southampton. ac.uk/assets/sharepoint/groupsite/Administration/SitePublisher-documentstore/Documents/aai_report.pdf

Christian Ernst Heinrich Boehler is a Health Economist at the European Centre for Social Welfare Policy and Research in Vienna (Austria). He obtained his PhD at Brunel Universities' Health Economics Research Group (HERG) in London (UK), and has years of experience in the conduct of economic evaluation of innovative health and care technologies. Previously, he worked as a scientific officer at the European Commission's Joint Research Centre (DG-JRC IPTS) in Seville (Spain), where he was in charge of developing a Monitoring and Assessment Framework for the European Innovation Partnership on Active and Healthy Ageing (MAFEIP-project). 
Timea Mariann Helter is an economist with a wide range of international work experience and education related to the health sector and is currently working for the Main Association of Austrian Social Security Institutions. She holds Masters degrees in economics, health informatics and health research. Timea is also experienced within the area of international health outcomes research through her positions at British, Hungarian and Austrian consultancy firms and the national Health Technology Assessment office in Hungary.

Ibrahim-Kholilul Rohman is a PhD in Technology Management of Economics from Chalmers University of Technology. Ibrahim is a Research Fellow at the United Nations University Operating Unit on Policy-Driven Electronic Governance (UNU-EGOV). His research analyses the role of eGov to combat the shadow economy in developing countries. Previously, he worked at the Information Society Unit, JRC IPTS prior to joining UNU. He was in charge in the project called Prospective Insights on R\&D in ICT (PREDICT).

Fabienne Abadie, Scientific Officer at JRC Seville since 2006, managed a research team working on research projects in the field of eHealth until 2015. She led the Strategic Intelligence Monitor on Personal Health Systems (SIMPHS), a multi-annual project on remote patient monitoring and telehealth developments and the Monitoring and Assessment Framework for the European Innovation Partnership on Active and Healthy Ageing (MAFEIP) project whose aim was to assess the impact of European Innovation Partnership on Active and Healthy Ageing (EIP on AHA) initiatives. 